\title{
The Development of a Physical Spinal Cord Surrogate with Localized Transverse Compression Sensing Capabilities
}

\author{
Yann Facchinello ${ }^{1,3}$, Eric Wagnac ${ }^{1,2}$, Bora Ung ${ }^{2}$, Yvan Petit $^{1,2}$, Prabin Pradhan $^{2}$, Louis-Marie Peyrache Pr, $^{1,2}$ \\ and Jean-Marc Mac-Thiong ${ }^{1,3}$ \\ ${ }^{1}$ Research Center, Hôpital du Sacré-Cœur de Montréal \\ 5400, Gouin Boul. West, Montreal, Quebec, H4J 1C5, Canada \\ ${ }^{2}$ École de technologie supérieure \\ 1100 Notre-Dame Street West, Montreal, Quebec, H3C 1K3, Canada \\ ${ }^{3}$ Department of Surgery, Faculty of Medicine, University of Montreal, Pavillon Roger-Gaudry \\ S-749, C.P. 6128, succ. Centre-ville, Montreal, Quebec, H3C 3J7, Canada \\ yann.facchinello@gmail.com
}

\section{Extended Abstract}

Traumatic spinal cord injury (TSCI) occurs at an annual incidence of 10 to 60 cases per millions of inhabitants depending on the country [1]. TSCI can potentially damage motor and sensory function, leading to a loss of autonomy and a poor quality of life. Burst fractures and fracture dislocations are responsible for respectively $30 \%$ and $40 \%$ of all TSCI [1]. During those injuries, the spinal canal can be compromised by bone fragments, ligaments or other structures moving at high velocity toward the spinal cord. The compression magnitude and rate applied to the spinal cord define the extend of the neurological injury but because of the transient nature of the event, the biomechanics of the injury is poorly understood.

In vitro replication of the fracture is justified by the need to better understand the biomechanics of the injury. This information is needed to correlate loading conditions and fracture patterns with the mechanical impairment of the spinal cord [2]. Several studies investigated the dynamic events occurring during the replication of burst type fractures [3-6] while other researchers developed spinal canal occlusion sensors in an attempt to estimate the transient spinal cord compression occurring during the trauma [5, 7-10]. However, there is no published technology allowing the quantification of the internal strain occurring within the spinal cord during in vitro replication of the trauma. This communication describes an instrumented spinal cord surrogate with localized transverse compression sensing capabilities.

The spinal cord physical surrogate was made of silicone rubber foam (FlexFoam-iT! III, Smooth-on, PA, USA). The liquid silicon was quickly poured into a 3D printed ABS casting mold. The resulting silicone cord was $20 \mathrm{~cm}$ long and had an ellipsoidal section (major diameter of $11 \mathrm{~mm}$ and minor diameter of $9 \mathrm{~mm}$ ) replicating the human thoracic spinal cord transverse section [11]. During casting and curing of the silicone rubber foam, four $0.5 \mathrm{~mm}$ diameter nylon wires ran longitudinally through the surrogate. After silicone curing, the wire was removed and replaced by four $250 \mu \mathrm{m}$ diameter bare optical fibers. The sensing technology was based on the optical power loss occurring when an optical fiber is bent to a given curvature radius, with smaller radii leading to more power loss [12]. As the surrogate is being compressed, the optical fiber bends to adapt to its shape, leading to a decreasing optical power transmitted by the fiber as its curvature radius decreases.

The hyperelastic mechanical behavior of fresh porcine spinal cord was well reproduced by the instrumented surrogate with a maximum deviation of $16 \%$ when comparing the stress-strain curves obtained following mechanical characterization. Excellent sensing capabilities were observed for both static and dynamic loading with a maximum error of 5\% when comparing the compression magnitude recorded by the optical fibers with the displacement of the tensile testing apparatus. This communication describes the first technology capable of an accurate, localized and dynamic recording of the internal strain occurring within the spinal cord during in vitro burst fracture replication. 


\section{References}

[1] A. Singh, L. Tetreault, S. Kalsi-Ryan, A. Nouri, and M. G. Fehlings, "Global prevalence and incidence of traumatic spinal cord injury," Clin Epidemiol, pp. 309-31, 2014.

[2] R. M. Hall, R. J. Oakland, R. K. Wilcox, and D. C. Barton, "Spinal cord-fragment interactions following burst fracture: an in vitro model," J Neurosurg Spine, vol. 5, pp. 243-50, 2006.

[3] N. T. Tran, N. A. Watson, A. F. Tencer, R. P. Ching, and P. A. Anderson, "Mechanism of the burst fracture in the thoracolumbar spine. The effect of loading rate," Spine (Phila Pa 1976), vol. 20, pp. 1984-8, 1995.

[4] M. M. Panjabi, M. Kifune, L. Wen, M. Arand, T. R. Oxland, R. M. Lin, et al., "Dynamic canal encroachment during thoracolumbar burst fractures," J Spinal Disord, vol. 8, pp. 39-48, 1995.

[5] J. W. Carter, S. K. Mirza, A. F. Tencer, and R. P. Ching, "Canal geometry changes associated with axial compressive cervical spine fracture," Spine (Phila Pa 1976), vol. 25, pp. 46-54, 2000.

[6] R. K. Wilcox, T. O. Boerger, R. M. Hall, D. C. Barton, D. Limb, and R. A. Dickson, "Measurement of canal occlusion during the thoracolumbar burst fracture process," Journal of Biomechanics, vol. 35, pp. 381-384, 2002.

[7] R. P. Ching, N. A. Watson, J. W. Carter, and A. F. Tencer, "The effect of post-injury spinal position on canal occlusion in a cervical spine burst fracture model," Spine (Phila Pa 1976), vol. 22, pp. 1710-5, 1997.

[8] G. C. Raynak, D. J. Nuckley, A. F. Tencer, and R. P. Ching, "Transducers for dynamic measurement of spine neural-space occlusions," J Biomech Eng, vol. 120, pp. 787-91, 1998.

[9] D. J. Nuckley, M. A. Konodi, G. C. Raynak, R. P. Ching, J. R. Chapman, and S. K. Mirza, "Neural space integrity of the lower cervical spine: effect of anterior lesions," Spine (Phila Pa 1976), vol. 29, pp. 642-9, 2004.

[10] Q. Zhu, C. Lane, R. P. Ching, J. D. Gordon, C. G. Fisher, M. F. Dvorak, et al., "Translational constraint influences dynamic spinal canal occlusion of the thoracic spine: An in vitro experimental study," Journal of Biomechanics, vol. 41, pp. 171-179, 2008.

[11] H. Y. Ko, J. H. Park, Y. B. Shin, and S. Y. Baek, "Gross quantitative measurements of spinal cord segments in human," Spinal Cord, vol. 42, pp. 35-40, 2004.

[12] D. A. Krohn, T. W. MacDougall, and A. Mendez, Fiber Optic Sensors: Fundamentals and Applications, Fourth ed., 2015. 